\title{
Simulation of Surfactant Based Enhanced Oil Recovery
}

\author{
Wan Rosli Wan Sulaiman ${ }^{*}, 1,2$ and Euy Soo Lee ${ }^{1}$
}

\author{
${ }^{1}$ Department of Chemical and Biochemical Engineering, Dongguk University, 3-26, Pil-Dong, Chung-gu, Seoul, 100- \\ 715 Korea, ${ }^{2}$ Petroleum Engineering Department, Faculty of Petroleum and Renewable Energy Engineering, Universiti \\ Teknologi Malaysia, 81310 Skudai, Johor, Malaysia
}

\begin{abstract}
Surfactant flooding is an important process for enhanced oil recovery. A substantial amount of remaining oil resides in reservoirs especially in carbonate oil reservoirs that have low primary and water-flood oil recovery. Most of the surfactant flooding studies to date has been performed in water-wet sandstone reservoirs. As a result, the effects of heterogeneity and wettability of carbonates on surfactant flooding efficiency are fairly unknown. The purpose of this simulation study was to determine the effects of wettability and wettability alteration on Dodecylbenzene Sulfonate surfactant flooding in carbonate reservoirs. This study used the multi-phase, multi-component, surfactant flooding simulator called UTCHEM. The base case results showed that additional $27.8 \%$ of oil recovered after water-flooding process. Sensitivity analyses of key parameters such as chemical slug size and concentrations, salinity, reservoir heterogeneity and surfactant adsorption were performed to optimize a surfactant design for a mixed-wet dolomite reservoir. The study was then extended to simulating wettability alteration during the field scale surfactant flood. The results of modeling the wettability alteration showed that significant differences in injectivity and oil recovery are caused by the changes in the mobility of the injected fluid. As the use of surfactant flooding spreads into the reservoir especially oil-wet and mixed-wet reservoirs, the importance of surfactant-based wettability alteration will become important.
\end{abstract}

Keyword: Dodecylbenzene Sulfonate, surfactant, simulation, wettability, enhanced oil recovery.

\section{INTRODUCTION}

Surfactant flooding is an important technology for enhanced oil recovery. A substantial amount of remaining oil resides in reservoirs, many of these are carbonate reservoirs that have low primary and water-flood recovery as a result of poor sweep efficiency that has resulted in bypassed or unswept oil. Chemical flooding methods such as surfactant flooding have been shown to be effective in recovering this unswept oil. The basis for surfactant flood is to inject a surface-active agent (a surfactant) to reduce the interfacial tension and mobilize the residual oil saturation.

A few of the many examples of technically successful surfactant field projects reported in the literature. Gilliland and Conley [1] reported a pilot test for the Big Muddy Field in Wyoming. The reservoir was low-pressure wateredout sandstone with reasonably high remaining oil saturation and successfully increased the oil cut from $1 \%$ to $19 \%$ during peak production. Bragg et al. [2] reported results for a pilot test at Exxon's Loudon Field in Illinois. The field test was conducted in a watered-out portion of a sandstone reservoir. They were able to produce $60 \%$ of the residual oil saturation in spite of the high-salinity formation brine. Bae [3] reported a flooding project in Chevron's Glenn Pool Field in Oklahoma. They produced one-third of the residual

\footnotetext{
*Address correspondence to this author at the Department of Chemical and Biochemical Engineering, Dongguk University, 3-26, Pil-Dong, Chung-gu, Seoul, 100-715, Korea; Tel: +82-10-8320-2711;

Fax: +82-2-2266-1848; E-mail: r-wan@petroleum.utm.my
}

oil saturation from shallow, low-permeability sandstone. Putz et al. [4] reported results for a micro-emulsion pilot in the Chateaurenard field. They report $68 \%$ of the residual oil was recovered in this pilot. Holm and Robertson [5] and Widmeyer et al. [6] also reported successful pilot tests.

One example of a surfactant flooding project in a carbonate reservoir was reported by Adams et al. [7]. They presented a flooding pilot test for two well pairs in a San Andreas dolomite reservoir in West Texas. Based on a tracer test, the residual oil saturation to surfactant flooding was $7.5 \%$ for one of the well pairs and $18 \%$ for the other. The key reservoir properties affecting the surfactant flood were the heterogeneity and high salinity. This project is one of the few that studies surfactant flooding in a carbonate setting.

Oil recovery during surfactant flooding is heavily impacted by the petrophysical and petrochemical properties controlled by the wettability of a reservoir. Historically, all petroleum reservoirs were said to be strongly water-wet. This theory is based on the fact that all clean sedimentary rocks are strongly water-wet and reservoir rocks are created during sediment deposition amongst an aqueous phase [8]. In the 1930s, this theory was questioned and evidence showed that the wettability of different minerals could be altered by adsorption of organic matter from crude oils creating different types and degrees of wettability.

A carbonate rock, which tends to adsorb simple organic acids from crude oils [8], will commonly have weakly wetting conditions. Chilingar and Yen [9] have shown that 
carbonate reservoir rocks are commonly weakly oil-wet. On the other hand, a sandstone rock, which tends to adsorb simple organic bases [8], is expected to be primarily waterwet. Conversely, Treiber et al. [10] reported that sandstone reservoirs do not have a common wettability condition. Also, a rock can have mixed wettability [11].

\subsection{Past Simulations of Surfactant Flooding}

Using reservoir simulators to predict and understand the processes taking place during surfactant flooding is currently of renewed interest to the industry due to high current oil prices and thus the greatly increased interest in enhanced oil recovery. Over the past 30 years, surfactant flooding simulators have become more and more complex. In addition, the need for accurate surfactant flooding prediction is more important as enhanced oil recovery projects are getting more attention. Pope and Nelson [12], Todd and Chase [13], Dogru et al. [14], Datta-Gupta et al. [15] and Scott et al. [16] were among the first to publish papers on surfactant flooding simulators.

Chemical flood simulators are used in academia and industry to help understand, optimize, interpret and design surfactant flooding processes. As with other simulators, surfactant flooding simulators are often used to history match and understand the results of core floods or field performance. In one example, Saad et al. [17] used the Chemical Compositional Simulator [UTCHEM] developed by University of Texas to history match surfactant flood and found among other things that caution exchange was an important factor in the success of the flood.

Kalpakci et al. [18] used a modified version of UTCHEM simulator to study and focused on harsh reservoir conditions such as high salinity and high temperature. The design was obtained by up-scaling from core-flood experiments to field scale. They determined that injecting a large slug of chemicals at low concentrations is optimum based on economics. The large up-front cost of chemicals derived from a small slug with high concentration can produce adverse economic results.

$\mathrm{Wu}$ [19] studied the surfactant flooding optimization for several field scale projects. His focus was primarily on onshore sandstone reservoirs, and his optimization study focused on chemical concentrations, slug sizes, and adsorption. In addition, an economic analysis was used to determine the optimum design. He concluded that a large surfactant slug size at low concentrations was the optimum design. However, it is important to understand that his results were heavily dependent on the low price of oil at the time of his study and on an assumed very low value of surfactant adsorption.

\section{METHODOLOGY}

This study divided into two phases, the first phase is a core-flood in a laboratory to obtain certain reservoir parameters such as porosity, permeability, initial oil and water saturation and permeability curve. These data are important to be incorporated into the simulator as the feed parameters. The second phase is a simulation to predict the performance and additional oil recovery under certain improved parameters such as slug size and surfactant concentration.

\subsection{Simulation Model}

The first step in this study was to develop a simulation model representative of the reservoir. The field operator provided properties such as reservoir dimensions, petrophysical parameters, and fluid properties. The reservoir is 4,700 feet deep, $100^{\circ} \mathrm{F}, 100$ feet thick, and has petrophysical properties indicative of a mixed-wet rock. Table 1 shows some of the petrophysical properties used in this study. The reservoir has uncharacteristically high residual oil saturation for a mixed-wet rock. However, studies like Tie and Morrow [20] show that this range of residual oil saturation is common in a carbonate rock. The reservoir fluid properties were also obtained from the field operator. Table 2 shows the fluid properties used in this study.

Table 1. Reservoir and Simulation Model Properties

\begin{tabular}{|c|c|}
\hline Model Physical Dimensions & $700^{\prime}$ x 800' x 100' \\
\hline Depth & 4,700 feet \\
\hline Porosity & $\begin{array}{l}\text { Average }=0.16 \\
\operatorname{Min}=0.06 \\
\operatorname{Max}=0.273\end{array}$ \\
\hline Permeability & $\begin{array}{l}\text { Average }=156 \mathrm{mD} \\
\operatorname{Min}=4.4 \mathrm{mD} \\
\operatorname{Max}=870 \mathrm{mD} \\
\mathrm{k}_{\mathrm{V}} / \mathrm{k}_{\mathrm{h}}=0.05\end{array}$ \\
\hline Residual saturations & $\begin{array}{l}\text { Water }=0.3 \\
\text { Oil }=0.42\end{array}$ \\
\hline $\begin{array}{l}\text { Corey type relative permeability } \\
\text { endpoint }\end{array}$ & $\begin{array}{l}\text { Water }=0.4 \\
\text { Oil }=0.6\end{array}$ \\
\hline $\begin{array}{l}\text { Corey type relative permeability } \\
\text { exponent }\end{array}$ & $\begin{array}{l}\text { Water }=2 \\
\text { Oil }=2\end{array}$ \\
\hline Simulation model pore volume & 1.610 MMbbl \\
\hline $\begin{array}{l}\text { Simulated post waterflood average } \\
\text { saturations }\end{array}$ & $\begin{array}{l}\text { Water }=0.53 \\
\text { Oil }=0.47\end{array}$ \\
\hline $\begin{array}{l}\text { Simulated post waterflood oil in } \\
\text { place }\end{array}$ & $0.75 \mathrm{MMbbl}$ \\
\hline $\begin{array}{l}\text { Simulated post waterflood average } \\
\text { reservoir pressure }\end{array}$ & $755 \mathrm{psi}$ \\
\hline
\end{tabular}

A simulation model was developed according to these properties. The model was developed as a quarter 5-spot symmetry element with a pressure-constrained injector and producer. The symmetry element was based on a 40-acre well spacing, which is relatively large for surfactant flooding. The field operator also provided the producer 
and injector well constraints (300 psi and 2,500 psi bottom-hole, respectively), which were based on facility and reservoir fracture gradient limitations. The permeability field used in this model was developed by the field operator and is shown in Fig. (1). As depicted in the figure, the reservoir is heterogeneous with high permeability layers in the middle and the top.

\section{Table 2. Fluid Properties}

\begin{tabular}{|l|l|}
\hline Density & $\begin{array}{l}\text { Oil }=\mathbf{3 1}{ }^{\circ} \mathbf{A P I}(\mathbf{0 . 8 7} \mathbf{g} / \mathbf{m l}) \\
\text { Water }=\mathbf{1} \mathbf{~} / \mathbf{c c}\end{array}$ \\
\hline \hline \multirow{2}{*}{ Viscosity } & Water $=0.72 \mathrm{cp}$ \\
& Oil $=5 \mathrm{cp}$ \\
\hline & Overall $=1 \mathrm{meq} / \mathrm{mL}$ \\
& $\mathrm{Ca}^{2+}=2,066 \mathrm{ppm}$ \\
& $\mathrm{Mg}^{2+}=539 \mathrm{ppm}$ \\
& $\mathrm{Na}^{+}=20,533 \mathrm{ppm}$ \\
& $\mathrm{SO}_{4}^{2+}=4,540 \mathrm{ppm}$ \\
& $\mathrm{Cl}^{-}=32,637 \mathrm{ppm}$ \\
\hline
\end{tabular}

This reservoir has had a long history of primary and secondary recovery. Therefore, a water-flood was simulated to obtain conditions similar to the current state of the reservoir. The simulation was run until a water cut of $98 \%$ was attained, resulting in 1.8 pore volumes injected. This simulation generated the initial oil saturation and pressure distribution for the surfactant flooding simulations. The average post-water-flood saturations and pressure are listed in Table 1. Fig. (2) shows the oil saturation distribution and the effect of the high permeability layers which had the lowest post- water-flood oil saturation.

\subsection{Surfactant Data}

The surfactant used in this study was Dodecylbenzene Sulfonate based on the screening of its properties. David et al. [21] developed a screening process for the surfactant phase behavior to determine the compatibility with the crude oil and the optimum surfactant/co- surfactant/solvent blend. These experiments were used to determine the optimum salinity and corresponding IFT. Following the laboratory's screening test, the optimum surfactant formulation and phase behavior was used in this simulation study. The UTCHEM surfactant phase behavior parameters were obtained by curve fitting the laboratory solubilization ratio for several salinities.

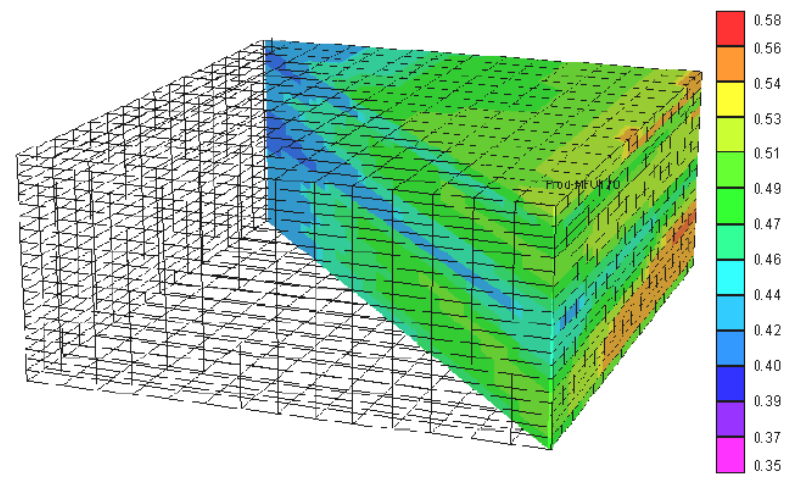

Fig. (2). Simulation model initial oil saturation.

\subsection{Laboratory Core-Floods}

In addition, Berea and reservoir core floods were conducted to measure the performance of the surfactant. In particular, the surfactant retention was measured in several core floods and ranged from 2 to $4 \mu \mathrm{g} / \mathrm{g}$ with an average value of $3 \mu \mathrm{g} / \mathrm{g}$. The dolomite cores contain anhydrite that is continuously dissolved at about $500 \mathrm{ppm}$ of $\mathrm{Ca}^{2+}$, so this level of $\mathrm{Ca}^{2+}$ pick up was accounted for in the design of injected slug and drive.

For this simulation study, the dissolution of $\mathrm{Ca}^{2+}$ was not modeled. The process was assumed to occur instantaneously in the field-scale simulations and the phase behavior properties accounted for the $\mathrm{Ca}^{2+}$ pick up at the initial conditions. Chemical screening experiments were conducted with $500 \mathrm{ppm} \mathrm{Ca}^{2+}$ initially and these data were matched to obtain the UTCHEM parameters. Fig. (3) shows the relative permeability data obtained from the core flood analysis.

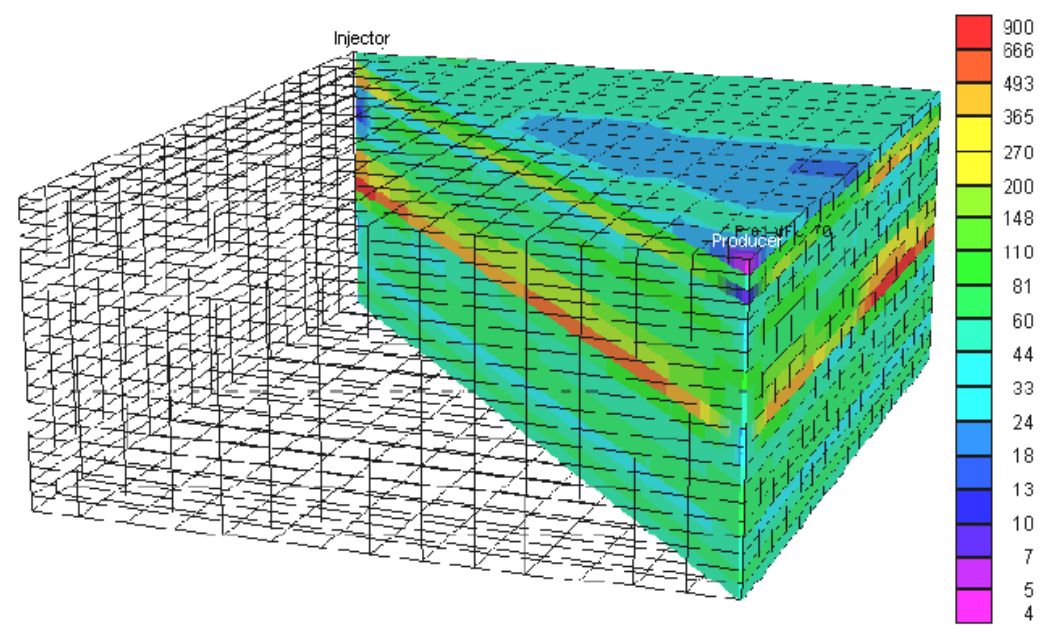

Fig. (1). Simulation model permeability $(\mathrm{mD})$. 


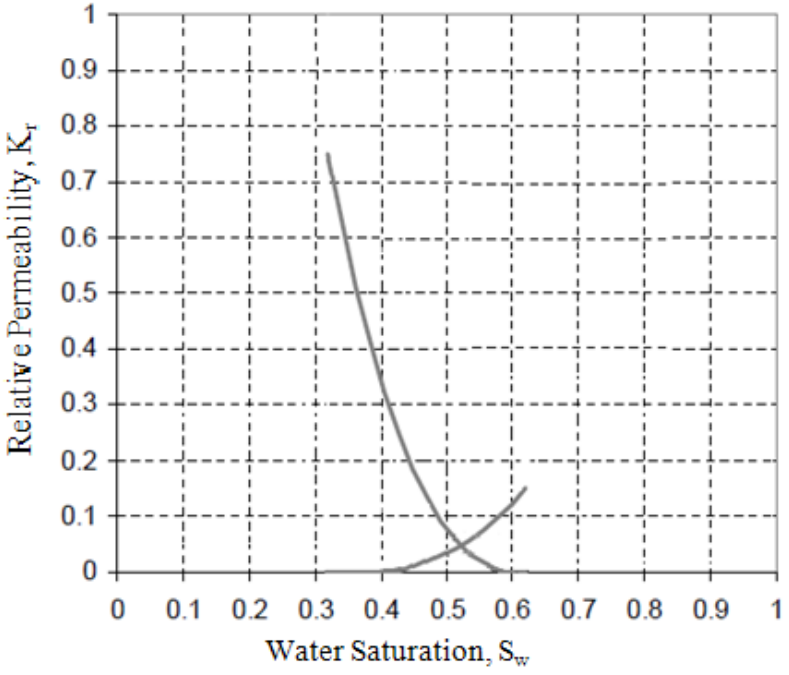

Fig. (3). Relative permeability at different water saturation.

\subsection{Base Case Surfactant Design}

Following the analysis of the laboratory data, a base case design was established. The base case simulation used the previously discussed well constraints and initial conditions. The well constraints are important for surfactant flooding because they can affect the life of the project. The surfactant flooding design was partly based on the laboratory core flood design. The laboratory design was used as the starting point but was up-scaled for a field size application. Table 3 shows a summary of base case design including slug sizes, chemical concentrations, and salinity.

Table 3. Base Case Surfactant Design

\begin{tabular}{|l|l|}
\hline Injection well constraints & $\begin{array}{l}\text { Rate constraint }=\mathbf{2 , 0 0 0} \text { bbl/day } \\
\text { Pressure control = 2,500 psi }\end{array}$ \\
\hline \hline Production well constraint & Pressure constraint = 300 psi \\
\hline Surfactant slug & $0.25 \mathrm{PV}$ \\
& $1 \mathrm{vol} \%$ surfactant \\
& $1,000 \mathrm{ppm}$ polymer \\
& $0.365 \mathrm{meq} / \mathrm{mL}(21,000 \mathrm{ppm}$ TDS $)$ \\
\hline \multirow{2}{*}{ Polymer drive } & $1 \mathrm{PV}$ \\
& $1,000 \mathrm{ppm}$ polymer \\
\hline Water postflush & $0.2 \mathrm{meq} / \mathrm{mL}(11,700 \mathrm{ppm}$ TDS $)$ \\
\hline Surfactant adsorption & $0.5 \mathrm{PV}$ \\
\hline Capillary desaturation & $0.04 \mathrm{meq} / \mathrm{mL}(2,300 \mathrm{ppm}$ TDS $)$ \\
\hline parameters & $0.3 \mathrm{mg}$ surfactant/g rock \\
\hline Vertical permeability & Water $=1,865$ \\
\hline
\end{tabular}

This design consisted of a $0.25 \mathrm{PV}$ surfactant slug. The salinity gradient was also derived from laboratory experiments and can be a key parameter for the success of a chemical flood. The salinity gradient was important for this study because of the extreme changes in salinity throughout the chemical flood.

There were also several assumed values that went into the model. A value of surfactant adsorption was conservatively chosen within the values reported by the laboratory. The value used was slightly higher than the average lab value $(0.3 \mathrm{mg} / \mathrm{g}$ compared to $0.2 \mathrm{mg} / \mathrm{g})$. The capillary desaturation curve was also assumed using parameters as presented in Delshad [22]. The last assumption dealt with permeability. A ratio of vertical to horizontal permeability of 0.05 was used based on a recommendation from the field operator, but the actual value is unknown. An assumed value for the average permeability was used to correspond to the best part of the field. There are other regions in the field that have significantly lower permeability.

\section{RESULTS AND DISCUSSIONS}

The resulting curve fit for surfactant data is shown in Fig. (4). The optimum salinity for this surfactant/crude oil/brine solution was relatively high. The surfactant blend was designed in this fashion since the reservoir salinity of $\sim 33,000 \mathrm{ppm}$ is high. In addition, the IFT at optimum salinity is quite low. Using the Chen et al. [23] equation and the solubilization ratio at optimum salinity, an approximate value of $0.001 \mathrm{dynes} / \mathrm{cm}$ was expected.

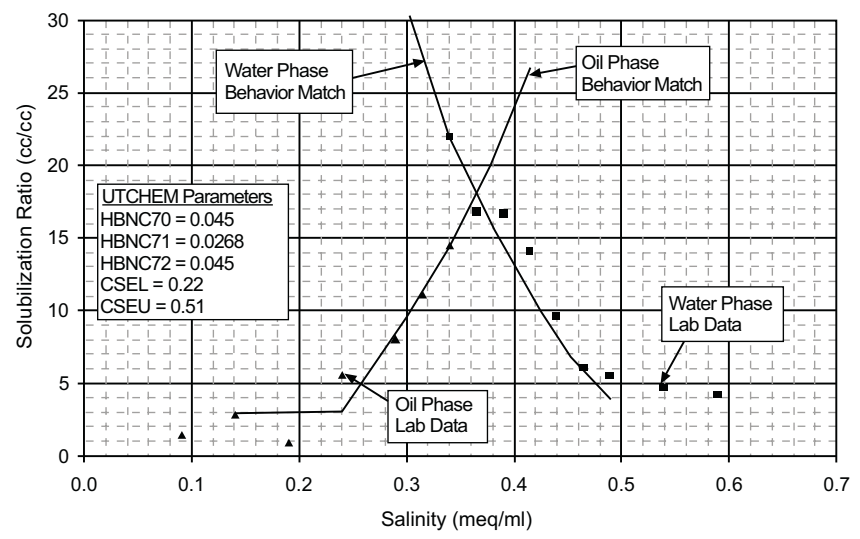

Fig. (4). Comparison of measured and UTCHEM surfactant phase behavior.

\subsection{Base Case Results}

Note that all fluid rates, masses, and volumes were reported for a full five-spot pattern even though the simulation model was a quarter of a five-spot symmetry element. Fig. (5) shows the base case injection rate and pressure throughout the chemical flood. The figure displays the changes in injection rate during each simulation phase. Fig. (6) shows the base case production rates and produced surfactant concentration throughout the chemical flood.

One important observation of surfactant flooding was the change in production rates during the flood. For this simulation, a dramatic increase in oil production rate could be seen. The pre-chemical flood rate was 35 bbls of oil per day and increased to a peak value of 720 bbls/day Fig. (6). 
This corresponded to an increase in oil cut from $2 \%$ to $35 \%$. Another important result shown in this curve was the breakthrough time of oil and surfactant (0.25 PV and 0.35 $\mathrm{PV}$, respectively). The surfactant concentrations were low $(<0.001$ volume fraction) compared to the injected values (0.01 volume fraction). The base case simulation had a reasonable surfactant flooding cumulative oil recovery. The recovery was $27.8 \%$ of the original oil in place which is $42 \%$ of the remaining oil in place after water-flooding.

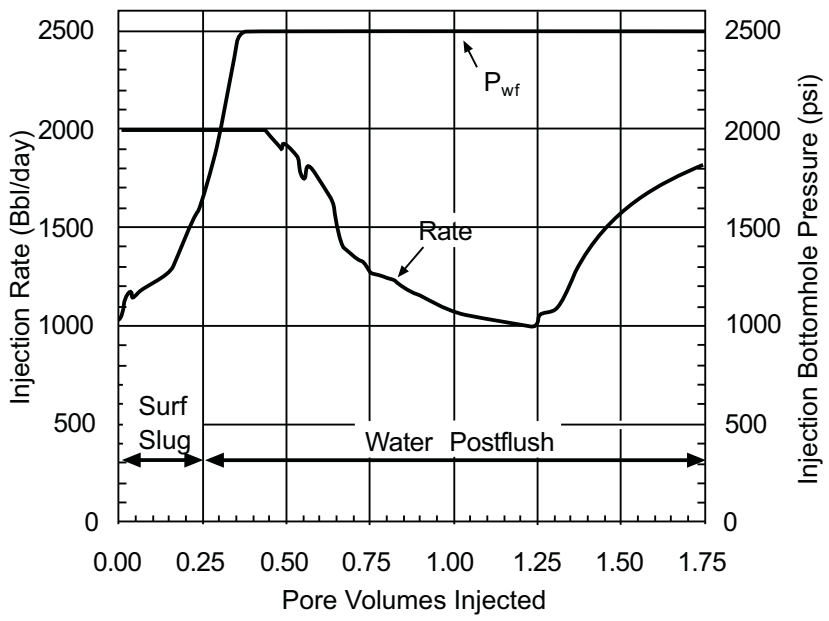

Fig. (5). Injection rate and bottom-hole pressure profiles for base case simulation showing the injection rate was reduced to maintain the maximum bottom-hole pressure.

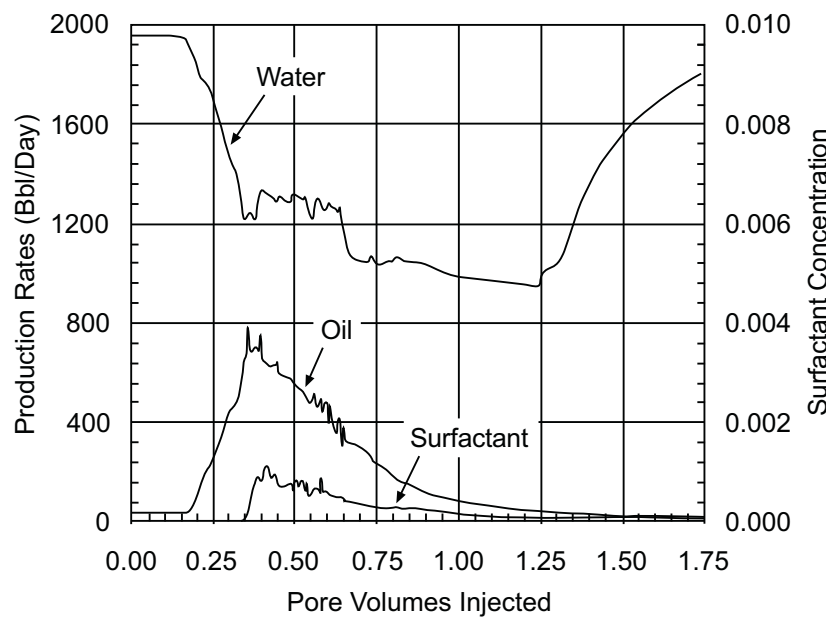

Fig. (6). Oil and water production profiles for base case simulation. Oil production decrease after 0.35 pore volume of surfactant and water injected. Produced surfactant concentration also reduced with time.

The oil saturation was reduced to very low values in the high permeability layer at early times. One key result was the very low oil saturations near the injection well and in the high permeability layers. Figs. (7-9) show the base case oil saturation distribution at different times of the chemical flood. The figures show one three-dimensional profile of a slice through the wells and one 2D areal cross section of the high permeability middle layer. At the final time, a significant amount of oil was left in the low permeability layers ( $56 \%$ oil saturation).

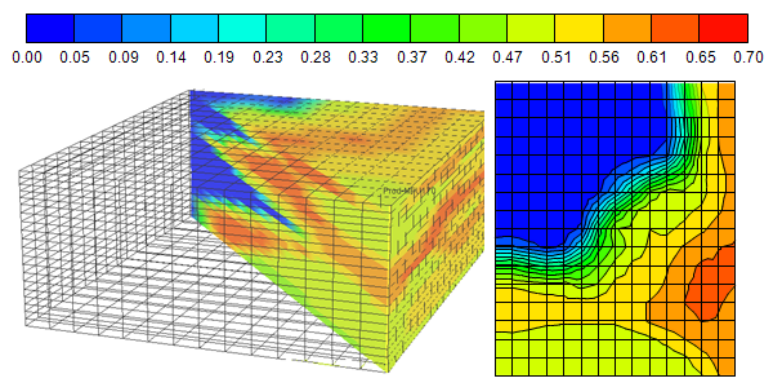

Fig. (7). Base case oil saturation distribution after 0.2 pore volume of surfactant injected.

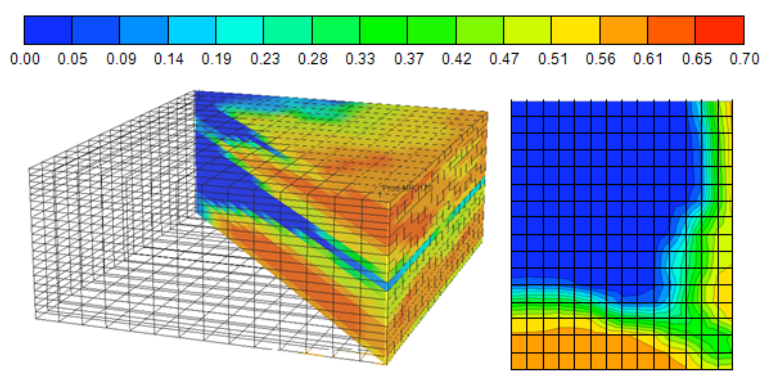

Fig. (8). Base case oil saturation distribution after 0.35 pore volume of surfactant and water injected to the reservoir, surfactant and water start to breakthrough at the middle of reservoir.

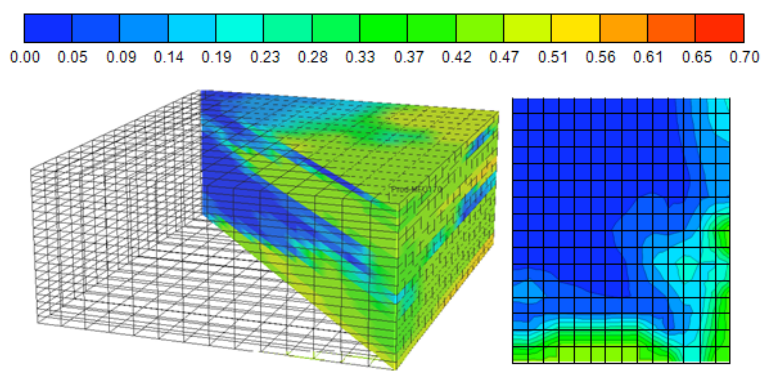

Fig. (9). Base case oil saturation distribution after 1.75 pore volume of surfactant and water injected to the reservoir, most of the oil recovered from the reservoir.

The surfactant concentration profiles show that the surfactant moved very quickly through the high permeability layers resulting in early breakthrough. The profiles of surfactant concentration at different times are shown in Fig. (10-12). Due to adsorption and production, almost no surfactant was left at the final time.

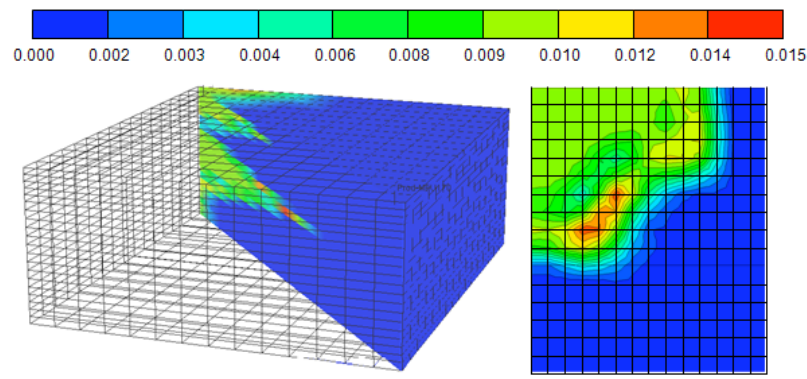

Fig. (10). Base case surfactant concentration distribution after 0.2 pore volume injected, surfactant spreading all over the wellbore. 


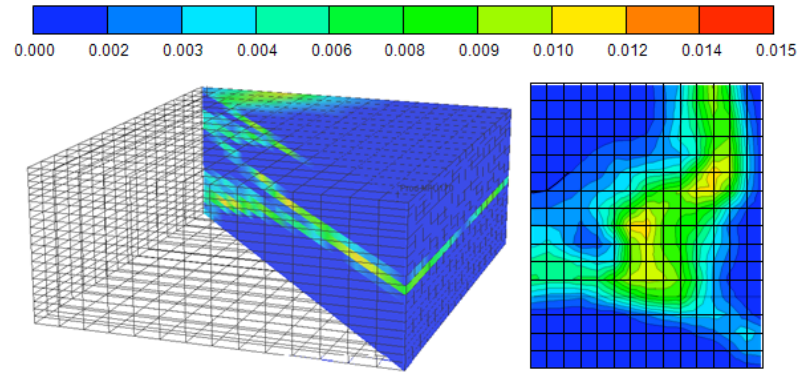

Fig. (11). Base case surfactant concentration distribution after 0.35 pore volume of surfactant and water injected. Two dimensional cross section clearly shows surfactant evenly distributed and pushed by the water.

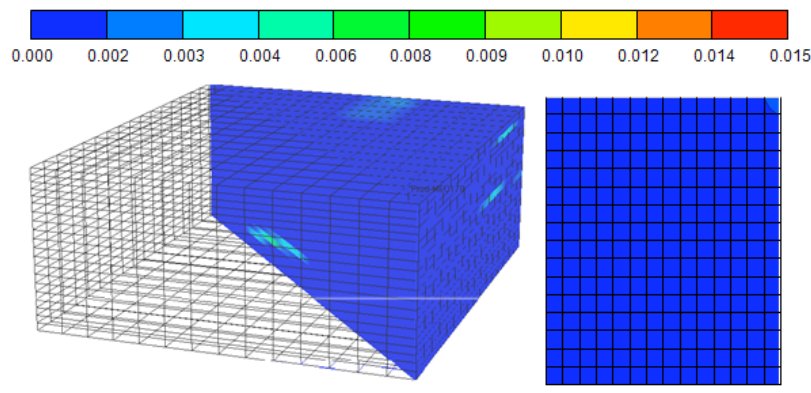

Fig. (12). Base case surfactant concentration distribution after 1.75 pore volume of surfactant and water injected to the reservoir shows most of the surfactant washed out and produced at the producer well.

The interfacial tension was reduced to very low values near the well and in the high permeability layers. The profiles of IFT at different times are shown in Figs. (13-15). These figures depicted the same results as the surfactant concentration profiles. This un-optimized base case simulation resulted in very promising oil recovery $(27.8 \%$ OOIP).

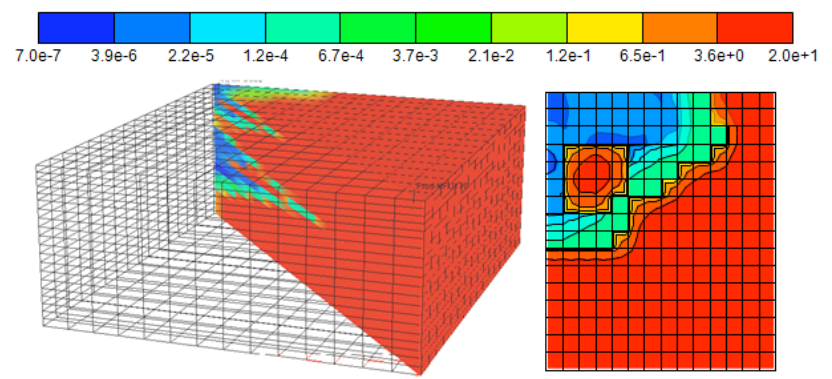

Fig. (13). Base case interfacial tension (dynes/cm) distribution after 0.2 pore volume of surfactant injected to the reservoir. The IFT value surrounding area of injector wellbore start to reduced.

\subsection{Sensitivity Analysis}

A sensitivity analysis is important because a chemical project has significant risks based on financial, process, and reservoir uncertainties. Chemical flood simulations are dependent on a large number of variables used for reservoir description, fluid and rock properties and process design. Following the assessment of the base case simulation, a method of testing the sensitivity of each key process variable was generated with the intent of obtaining the optimum surfactant design and observing the effects of uncertain design parameters.

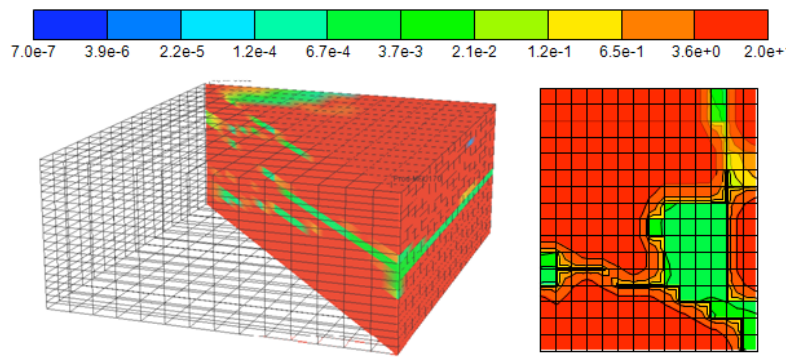

Fig. (14). Base case interfacial tension (dynes/cm) distribution after 0.35 pore volume of surfactant and water injected to the reservoir. The IFT of the reservoir reduced at the frontal area and increased again at the back because of water injected sweep the surfactant away.

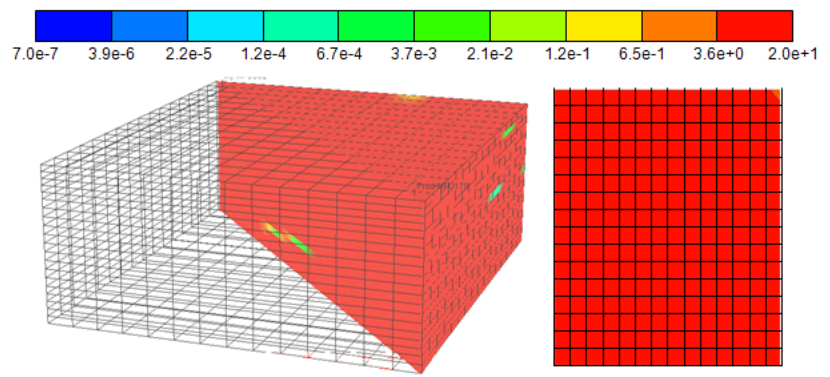

Fig. (15). Base case interfacial tension (dynes/cm) distribution after 1.75 pore volume of surfactant and water injected to the reservoir. The IFT value increase back to the normal value after all of the surfactant pushed out to the producer well.

All sensitivity simulations were performed by adjusting one parameter at a time and leaving the remaining parameters identical to the base case. Table 4 summarizes all of the sensitivity designs and their results. The key parameters are surfactant which strongly control the oil recovery and mobility controls.

Listed in Table $\mathbf{4}$ are the oil recovery, chemical efficiency, and simulation life. Chemical efficiency was calculated by dividing the mass of chemical injected (pounds) by the volume of oil recovered during the chemical flood (barrels). For the base case simulation, the oil and surfactant breakthrough times were $0.25 \mathrm{PV}$ and $0.35 \mathrm{PV}$, respectively. If the reservoir were water-wet, the oil bank breakthrough time would be faster and the surfactant breakthrough time would be slower than in this mixed-wet case. This phenomenon is due to fractional flow effects based on differences in relative permeability for the different wettability conditions. The mobility ratio for the simulated surfactant flood in this mixed-wet reservoir was approximately 1.3 . This mobility ratio for the same chemicals would have been about 0.6 for a water-wet reservoir, a much more favorable value [23].

\subsubsection{Sensitivity Parameters}

The parameters used in this analysis served the purpose of obtaining the optimum design and testing the effects of 
Table 4. Sensitivity Simulation Designs and Results

\begin{tabular}{|c|c|c|c|c|c|c|c|}
\hline $\begin{array}{l}\text { Run } \\
\text { No. }\end{array}$ & $\begin{array}{l}\text { Surf. Slug Size } \\
(\% \mathrm{PV})\end{array}$ & $\begin{array}{l}\text { Surf. Conc. } \\
(\text { vol\%) }\end{array}$ & $\begin{array}{l}\text { Surf. Mass } \\
\text { (MMlb) }\end{array}$ & Other Design Variable & $\begin{array}{c}\text { Cum. Oil Rec. } \\
\text { (\% OOIP) }\end{array}$ & $\begin{array}{c}\text { Surfactant } \\
\text { Efficiency } \\
\text { (lb/bbl oil) }\end{array}$ & $\begin{array}{l}\text { Chemical Cost } \\
\text { per barrel of oil }\end{array}$ \\
\hline 1 & 25 & 1 & 5.6 & N/A & $27.8 \%$ & 4.5 & $\$ 14.5$ \\
\hline \multicolumn{8}{|c|}{ Sensitivity variable: Surfactant concentration } \\
\hline 3 & 25 & 1.5 & 8.4 & N/A & $35.2 \%$ & 5.3 & $\$ 16.5$ \\
\hline \multicolumn{8}{|c|}{ Sensitivity variable: Surfactant slug size } \\
\hline 4 & 50 & 1 & 11.2 & N/A & $38.3 \%$ & 6.7 & $\$ 20.1$ \\
\hline 7 & 25 & 1 & 5.6 & $\begin{array}{l}\text { Surf slug salinity } \\
=0.25 \mathrm{meq} / \mathrm{mL}\end{array}$ & $27.9 \%$ & 4.5 & $\$ 14.5$ \\
\hline 8 & 25 & 1 & 5.6 & $\begin{array}{l}\text { Drive salinity } \\
=0.15 \mathrm{meq} / \mathrm{mL}\end{array}$ & $27.8 \%$ & 4.5 & $\$ 14.5$ \\
\hline \multicolumn{8}{|c|}{ Sensitivity variable: Surfactant adsorption } \\
\hline 9 & 25 & 1.0 & 5.6 & $2 \mu \mathrm{g} / \mathrm{g}$ & $39.2 \%$ & 3.3 & $\$ 10.8$ \\
\hline 10 & 25 & 1.0 & 5.6 & $4 \mu \mathrm{g} / \mathrm{g}$ & $27.4 \%$ & 4.5 & $\$ 14.5$ \\
\hline 15 & 25 & 1 & 5.6 & Avg. Perm. $=78 \mathrm{mD}$ & $27.3 \%$ & 5 & $\$ 16.3$ \\
\hline \multicolumn{8}{|c|}{ Uncertainty variable: Capillary desaturation curve } \\
\hline 16 & 25 & 1 & 5.6 & $\begin{array}{l}\text { High oil critical } \\
\text { capillary number }\end{array}$ & $25.2 \%$ & 5 & $\$ 16.5$ \\
\hline
\end{tabular}

${ }^{1}$ Assuming a surfactant cost of $\$ 2.75$ per pound.

key uncertain parameters. The parameters used to obtain the optimum design were surfactant concentration, surfactant slug size, and salinity. The value used for surfactant concentration affects the surfactant mass affecting both the oil recovery and economics of the project. Changes in surfactant concentration also affect the retardation factor of the surfactant slug. The retardation factor or frontal advance loss is defined as the loss of frontal velocity due to adsorption and has the units of pore volumes [24].

The surfactant slug size also affects the surfactant mass affecting both the oil recovery and economics. Changes in surfactant slug size will also result in slight changes in the salinity gradient. A longer surfactant slug will have a less steep salinity gradient compared to a shorter surfactant slug.

Salinity gradient is the last parameter used for surfactant design optimization. The key effects of salinity gradient are the changes in surfactant phase behavior during the flood. Pope et al. [25] presented results that show maximizing the region of ultra-low interfacial tension is optimum for surfactant flooding. Their conclusion was to design the salinity gradient so that the front of the surfactant slug has greater than optimum salinity, the middle of the slug is at optimum salinity, and the tail of the slug has lower than optimum salinity. 


\subsubsection{Surfactant Concentration Results}

A range of surfactant concentrations from 0.5 to 1.5 vol\% were tested for comparison with the base case (1 vol\%). As expected, the surfactant concentration was directly related to the oil recovery. The base case simulation with $1 \mathrm{vol} \%$ surfactant concentration had an oil recovery of $27.8 \%$ OOIP whereas the lower concentration $(0.5$ vol\%) and higher concentration (1.5 vol\%) simulations had recoveries of $17.5 \%$ and $35.2 \%$, respectively. The simulations had a range in retardation factors from $0.3 \mathrm{PV}$ (1.5 vol\% surfactant) to $0.9 \mathrm{PV}$ ( 0.5 vol\% surfactant). Since the base case simulation was designed to inject a $0.25 \mathrm{PV}$ surfactant slug, it would be expected that these simulations would have very adverse results. However, recall that the surfactant primarily sweeps the high permeability layers. This means the calculated retardation factors, which were based on the entire reservoir pore volume, gave overestimates according to the actual swept pore volume.

Fig. (16) shows the comparison of oil recovery for the surfactant concentration simulations. The simultaneous change in surfactant mass and oil recovery resulted in differences in chemical efficiency for these simulations. The simulation with higher concentration gave a worse chemical efficiency $(\$ 16.5 / \mathrm{bbl})$ compared to the base case $(\$ 14.5 / \mathrm{bbl})$. Conversely, the simulation with lower concentration resulted in an improved efficiency $(\$ 13.5 / \mathrm{bbl})$. These values were calculated using a surfactant price of $\$ 2.75$ per pound. Therefore at these assumed prices, the simulation with the lower injected surfactant concentration was the optimum for this key parameter regardless of the adverse retardation factor.

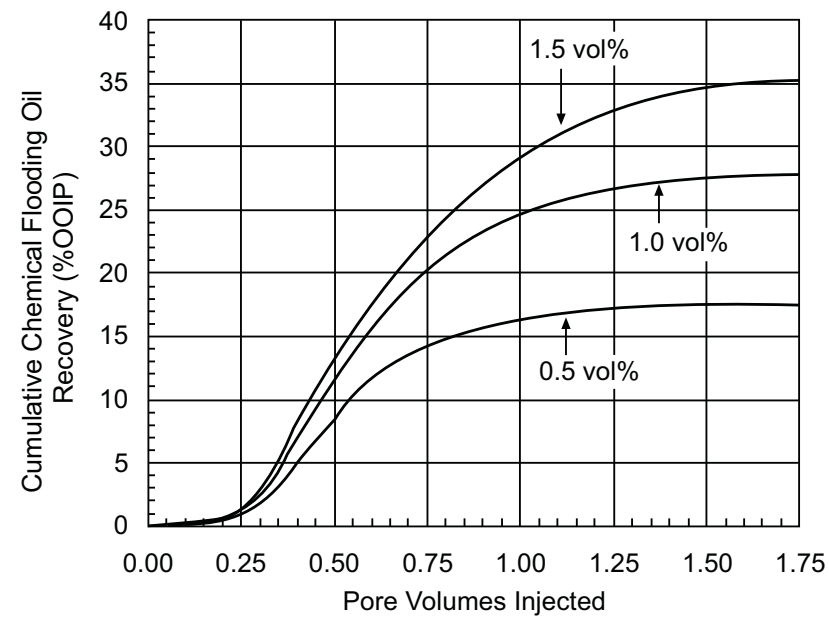

Fig. (16). Cumulative oil recovery profiles for different surfactant concentrations.

\subsubsection{Surfactant Slug Size Results}

Surfactant slug size was another key parameter studied in this sensitivity analysis. The higher slug size will cause a lower IFT inside the reservoir. The range of slug sizes tested was from $0.15 \mathrm{PV}$ to $0.5 \mathrm{PV}$. The results of these simulations are shown in Table $\mathbf{4}$ and a comparison of the cumulative oil recoveries for each are depicted in Fig. (17). Compared to the base case, the simulation with the highest oil recovery was the $0.5 \mathrm{PV}$ slug size as expected. This simulation was the only one that injected surfactant long enough to overcome the retardation factor. Even though the $0.5 \mathrm{PV}$ simulations had the highest oil recovery, it had the worst chemical efficiency $(\$ 20.1 / \mathrm{bbl})$. The simulation with the best chemical efficiency was the $0.15 \mathrm{PV}$ case which actually had the lowest recovery.

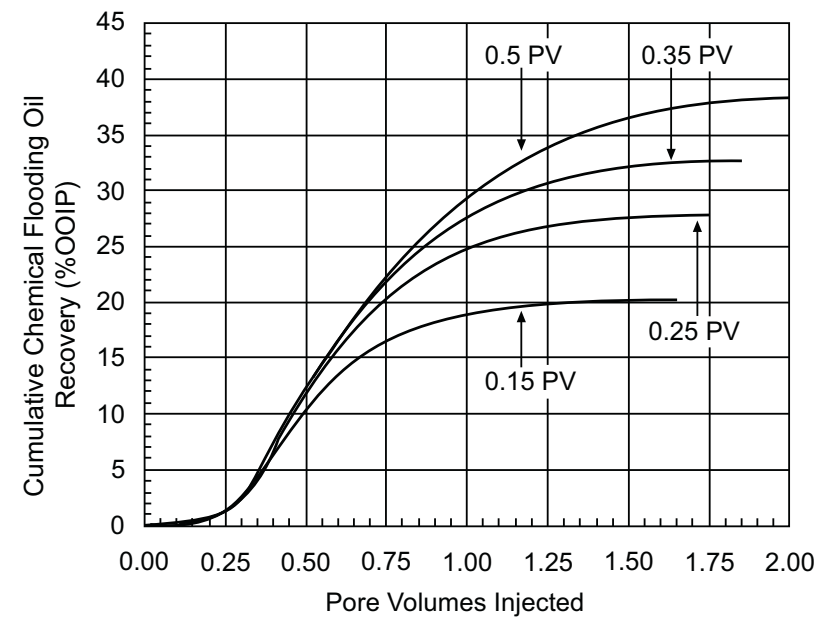

Fig. (17). Cumulative oil recovery profiles for different surfactant slug size.

\subsubsection{Salinity Gradient Results}

The last design optimization parameter was the salinity gradient. Sensitivity to the salinity gradient was analyzed by running two simulations. One of which was designed with a slightly lower slug salinity and the other with slightly lower polymer drive salinity. These simulations will affect the surfactant phase behavior and permeability reduction. The results of these simulations are shown in Table 4 . These simulations resulted in nearly identical oil recoveries and chemical efficiencies compared to the base case.

\subsection{Uncertainty Analysis}

The parameters used to study the reservoir and chemical uncertainty were surfactant adsorption, vertical to horizontal permeability ratio $\left(\mathrm{k}_{\mathrm{V}} / \mathrm{kh}\right)$, average permeability and the dependence of the oil saturation on capillary number. The surfactant adsorption was determined in laboratory experiments in a parallel study. As a result of that study, ranges of values for surfactant adsorption were presented. In this study, the effect of values within that range and beyond was tested. The primary effects of surfactant adsorption were changes in the retardation factor and the amount of surfactant required.

The vertical to horizontal permeability ratio is important for establishing reasonable vertical sweep efficiency during the surfactant flooding process. A value for this reservoir is 0.05 . A lower value of 0.01 was used in this uncertainty analysis. The permeability is variable within the reservoir in this study. The base case simulation model was based on the "sweet" spot of the reservoir that had the highest permeability. It was expected that lower permeability regions would have similar oil recovery but will have changes in permeability reduction and project life. As a result, the 
economics of the project would be drastically reduced. For this study, a permeability field with half the average horizontal permeability was simulated.

The last uncertain parameter was the oil capillary desaturation curve. The base case values used for this study were based on Delshad [22]. To test the effect of this parameter, a more adverse oil capillary number was simulated by shifting the oil capillary desaturation curve to the right. This can significantly affect oil recovery when low IFT is the primary mechanism.

\subsubsection{Surfactant Adsorption Results}

The first uncertainty parameter was surfactant adsorption. A range of values from $2 \mu \mathrm{g} / \mathrm{g}$ to $10 \mu \mathrm{g} / \mathrm{g}$ was tested. These values suggest a retardation factor ranging from $0.15 \mathrm{PV}$ to $0.9 \mathrm{PV}$, which can be compared to the surfactant slug size of $0.25 \mathrm{PV}$. Lower adsorption of surfactant will maintain the reservoir at lower IFT for a long time. As expected, the lower adsorption values gave higher oil recovery. The value closest to the most recent laboratory adsorption result using a reservoir core of $2 \mu \mathrm{g} / \mathrm{g}$ resulted in a significantly higher recovery of $39.2 \%$ OOIP. Fig. (18) shows a comparison of cumulative oil recovery for surfactant adsorption sensitivity analysis.

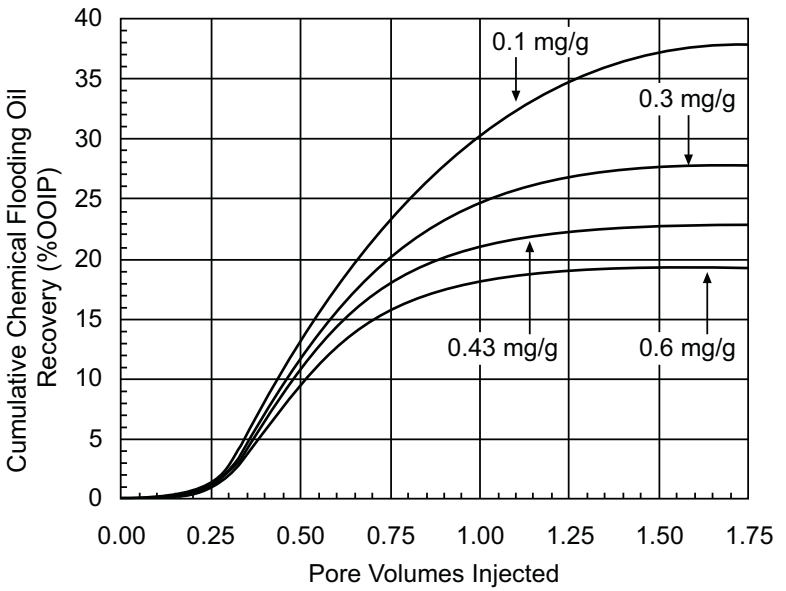

Fig. (18). Cumulative oil recovery profiles for different surfactant adsorption to the reservoir rock.

\subsubsection{Vertical Permeability Results}

The vertical to horizontal permeability ratio was also an uncertain parameter. A lower value of 0.01 was tested for comparison with the base case value of 0.05 . The result is shown in Table 4. A reduction in the $\mathrm{k}_{\mathrm{V}} / \mathrm{kh}_{\mathrm{h}}$ resulted in an unexpected increase in oil recovery (29\% OOIP). This simulation had higher channeling effects due to the lower $\mathrm{k}_{\mathrm{V}} / \mathrm{kh}$ resulting in less cross flow from the high permeability layers into the lower permeability layers. The increase in oil production came primarily from the upper permeability layer, which had improved areal sweep efficiency as a result of increased surfactant concentration throughout the flood.

\subsubsection{Horizontal Permeability Results}

The next uncertainty parameter was the reservoir permeability, which differs throughout the field. For this uncertainty simulation, the permeability used in the base case was reduced by a factor of two. It was expected that two effects would occur: extended simulation time and increased permeability reduction. The result is shown in Table 4 . The oil recovery was only slightly reduced to $27.3 \%$ OOIP but the simulation life was more than doubled. The reduction in permeability and the increase in permeability reduction severely reduced the injectivity. This uncertainty suggests that surfactant flooding the lower permeability region of this reservoir shows more risk and should be designed carefully.

\subsubsection{Capillary Desaturation Results}

The last uncertainty parameter was the oil capillary desaturation curve. The base case model assumed values provided in Delshad [22]. For this uncertainty simulation, a more adverse oil desaturation curve was used (lower oil trapping parameter with the curve moved to the right). The result is shown in Table 4. As expected, the oil recovery was reduced (25.2\% OOIP). However, the reduction in recovery is not as severe as it could have been.

\section{CONCLUSIONS}

The simulation model for this study was based on mixedwet dolomite reservoir. The field has undergone many years of water-flooding and is currently producing at $1-2 \%$ oil cut. The reservoir also has a high remaining oil saturation, which makes this field an EOR candidate. The reservoir, petrophysical, and fluid properties were obtained from the field operator and a simulation model was developed accordingly. The key property of the reservoir is the highly heterogeneous nature with noticeable layering.

A base case simulation was designed according to the laboratory core-flood design, which was scaled up to the field. The base case simulation resulted in a recovery of $28 \%$ OOIP. Most of the production was from the high permeability layers and resulted in early oil and surfactant breakthrough. A sensitivity analysis was performed to optimize the surfactant design. The surfactant mass was the key parameters studied. As expected, increasing the surfactant mass resulted in higher oil recovery. For example, additional $35.5 \%$ of OOIP was recovered by using $1.5 \mathrm{vol} \%$ of surfactant concentration. Lower recovery achieved at $17.5 \%$ of OOIP by using 0.5 vol\% of surfactant concentration. However, the economic results did not necessarily follow the same trend; higher surfactant concentration gave higher chemical cost per barrel of oil.

Surfactant slug size also plays major contribution to the oil recovery. Fifty percent pore volume of reservoir injected with surfactant gave highest recovery of $38.3 \%$ OOIP while only $20.2 \%$ of OOIP recovered when $15 \%$ pore volume used. This condition proves a higher volume of surfactant required in order recovering more oil from the reservoir but again the limitation in term of economic sentiment must be considered as well. A value of adsorption closest to the recent laboratory data gave very promising results. At higher adsorption rate, less oil will be recovered because the surfactant concentration will dramatically reduce and lost inside the reservoir. 
Other uncertainty results indicate that surfactant flooding this reservoir is profitable even with adverse conditions. For example, simulation result at low average reservoir permeability of $78 \mathrm{mD}$ gave additional $27.3 \%$ OOIP. This is significant indicator that by introducing this kind of surfactant into the reservoir, substantial amount of oil can be recovered from reservoir but subject to economical of the reservoir life.

The research presented was a preliminary study performed under time constraints. Given this constraint, a limited number of sensitivity parameters and simulations were run. In the future, the study should include other parameters including residual oil saturation, surfactant phase behavior, well spacing, and grid refinement. One important obstacle of this study was designing within the field's well constraints, an important design parameter that can affect the project life and chemical behavior during the flood. Another important obstacle was the reservoir heterogeneity and wettability. These are the most important factors affecting the surfactant flooding performance.

\section{CONFLICT OF INTEREST}

The authors confirm that this article content has no conflicts of interest.

\section{ACKNOWLEDGEMENTS}

The authors are grateful to Prof. Dr. Euy Soo Lee from Dongguk University for his critical discussions and supplying technical advices for this work.

\section{REFERENCES}

[1] H. E. Gilliland, and F. R. Conle, "A pilot test of surfactant flooding in the big muddy field", SPE Paper 5891, In: SPE Rocky Mountain Regional Meeting, May 11-12, Casper, WY USA, 1976.

[2] J.R. Bragg, W.W. Gale, W.A. McElhannon Jr., O.W. Davenport, M.D. Petrichuk, and T.L. Ashcraft, "Loudon surfactant flood pilot test", In: SPE Enhanced Oil Recovery Symposium, 4-7 April, Tulsa, OK, 1982.

[3] J.H. Bae, "Glenn pool surfactant-flood expansion project: A technical summary", In: SPE/DOE Improved Oil Recovery Symposium, Revised Paper 27818, January 25, Tulsa, OK, 1995.

[4] A. Putz, J.P. Chevalier, G. Stock, and J. Philippot, "A Field Test of Microemulsion Flooding, Chateaurenard Field, France", SPE Paper 8198, Annual Technical Conference Revised Paper, July 17, 1980.

[5] L.W. Holm, and S.D. Robertson, "Improved Micellar/Polymer Flooding With High-pH Chemicals", SPE Annual Technical Conference, Revised Paper 7583, July 28, 1980.

[6] R.H. Widmeyer, D.B. Williams, and J.W. Ware, "Performance evaluation of the salem unit surfactant/polymer pilot", Journal of Petroleum Technology, vol. 40, no. 9, pp. 1217-1226, 1988.

[7] W.T. Adams, and V.H. Schievelbein, "Surfactant flooding carbonate reservoirs", SPE Reservoir Engineering, vol. 2, no. 4, pp. 619-626, 1987.
[8] W.G. Anderson, "Wettability literature survey - part 1: rock/oil/brine interactions and the effects of core handling on wettability", Journal of Petroleum Technology, vol. 38, no. 10, pp. 1125-1144, 1986.

[9] G.V. Chilingar, and T.F. Yen, "Some notes on wettability and relative permeabilities of carbonate reservoir rocks", Energy Sources, vol. 7, no. 1, pp. 67-75, 1983.

[10] L.E. Treiber, D.L. Archer, and W.W. Owens, "A laboratory evaluation of the wettability of fifty oil producing reservoirs", SPE Journal, vol. 12, no. 6, pp. 531-540, 1972.

[11] R.A. Salathiel, "Oil recovery by surface film drainage in mixedwettability rocks", Journal of Petroleum Technology, vol. 25, no. 10, pp. 1216-1224, 1973.

[12] G.A. Pope, and R.C. Nelson, "A chemical flooding compositional simulator”, SPE Journal, vol. 18, no. 5, pp. 339-354, 1978.

[13] M.R. Todd, and C.A. Chase, "A numerical simulator for predicting chemical flood performance", In: SPE Paper 7689, Reservoir Simulation Symposium, February, Denver, CO, 1979.

[14] A.H. Dogru, H. Mitsuishi, and R.H. Yamamoto, "Numerical simulation of micellar polymer field processes", In: SPE Paper 13121, SPE Annual Technical Conference, September, Houston, TX 1984.

[15] A. Datta-Gupta, G.A. Pope, K. Sepehrnoori, and R.L. Thrasher, "A symmetric, positive definite formulation of a three-dimensional micellar/polymer simulator", SPE Reservoir Engineering, vol. 1, no. 6, pp. 622-632, 1986.

[16] T. Scott, S.R. Sharpe, K.S. Sorbie, P.J. Clifford, L.J. Roberts, R.W.S. Foulser, and J.A. Oakes, "A General Purpose Chemical Flood Simulator", SPE Paper 16029, In: Symposium on Reservoir Simulation, February, San Antonio, TX 1987.

[17] N. Saad, G.A. Pope, and K. Sepehrnoori, "Simulation of big muddy surfactant pilot", SPE Reservoir Engineering, vol. 4, no. 1, pp. 2434, 1989

[18] B. Kalpakci, T.G. Arf, J.W. Barker, A.S. Krupa, J.C. Morgan, and R.D. Neira, "The low- tension polymer flood approach to costeffective chemical EOR", SPE/DOE Paper 20220, April, pp. 475$488,1990$.

[19] W.J. Wu, "Optimum Design of Field-Scale Chemical Flooding Using Reservoir Simulation", Ph. D. Dissertation, The University of Texas, Austin, August, 1996.

[20] H. Tie, and N.R. Morrow, "Low Flood Rate Residual Saturations in Carbonate Rocks", In: International Petroleum Technology Conference, IPCT 10470, November, Doha, Qatar 2005.

[21] B.L. David, C.J. Adam, H. Christopher, N.B. Larry, M. Taimur, D. Varadarajan, and A.P. Gary, "Identification and Evaluation of High-Performance EOR Surfactants", SPE 100089, In: SPE/DOE Symposium on Improved Oil Recovery, 22-26 April, Tulsa, OK, 2006.

[22] M. Delshad, "Trapping of Micellar Fluids in Berea Sandstone", Ph.D. dissertation, The University of Texas, Austin, 1990.

[23] J. Chen, G. Hirasaki, and M. Flaum, "Study of Wettability Alteration From NMR: Effect of OBM on Wettability and NMR Responses", In: 8th International Symposium on Reservoir Wettability, May, 2004.

[24] L.W. Lake, Enhanced oil recovery, Prentice-Hall: Englewood Cliff, New Jersey, 1989.

[25] G.A. Pope, B. Wang, and T. Kerming, "A sensitivity study of micellar/polymer flooding", SPE Journal, vol. 19, no. 6, pp. 357368, 1979. 